Effects of providing total cost of ownership information on attribute weights in purchasing decisions

Sebastiaan Morssinkhof, Marc Wouters and Luk Warlop

DEPARTMENT OF MARKETING AND ORGANISATION STUDIES (MO) 


\title{
Effects of providing total cost of ownership information on attribute weights in purchasing decisions
}

\author{
Sebastiaan Morssinkhof ${ }^{1}$ \\ University of Twente \\ s.b.h.morssinkhof@utwente.nl \\ Marc Wouters \\ University of Twente \\ m.j.f.wouters@utwente.nl \\ Luk Warlop \\ Katholieke Universiteit Leuven \\ Luk.Warlop@econ.kuleuven.ac.be
}

January 2006

Acknowledgments: the authors like to thank Susan F. Haka, Joan Luft, participants at the Vrije Universiteit Amsterdam, 2005 MAS midyear meeting, and the 2005 Manufacturing Accounting Research seminar for comments on earlier versions of this paper.

\footnotetext{
${ }^{1}$ Data availability: please contact the authors.
} 


\title{
Effects of providing total cost of ownership information on attribute weights in purchasing decisions
}

\begin{abstract}
In this paper we investigate how the provision of total cost of ownership (TCO) information affects attribute weights in sourcing decisions, and how this effect is moderated by decision complexity. TCO quantifies the costs of each decision alternative for purchasing decisions, from the perspective of the buying organization. We consider incomplete TCO information, in that some non-financial attributes are not included in the TCO calculation, and we investigate unintended (and potentially disadvantageous) effects of providing decision makers with such information.

Experiments with 817 participants were conducted, both students and managers. We found moderate support for the hypothesis, that when complexity was low, participants gave a higher weight to the attribute that was excluded from the TCO information. We found support for the hypothesis that when complexity was high, decision makers gave less weight to this attribute, but this result was only found for the most experienced subgroup of managers. Experience did, however, not necessarily have a positive effect. Results suggest that, due to the provision of TCO information, experienced decision makers were more likely to follow an evaluation process in which less attention was paid to attributes that were not part of the TCO calculation. This suggests that experienced decision makers could be less mindful of the incompleteness of TCO information.
\end{abstract}




\section{INTRODUCTION}

In this study we investigate the use of accounting information for sourcing decisions and how this is affected by decision complexity and experience. Sourcing decisions are multiattribute decisions, whereby decision makers must consider several attributes of different purchasing options, and make tradeoffs among these attributes and alternatives. Total Cost of Ownership (TCO) accounting information aims to quantify the impact of all attributes on the total costs for the buying organization (Carr and Ittner 1992; Ellram 1995). As purchase prices are easy to compare, TCO information particularly aims to quantify the impact of other-thanprice differences (such as quality, lifetime, or energy use) on costs. TCO simulates a compensatory decision-making process, which would lead to optimal decisions with rational decision weights that are proportional to their impact on total cost. In other words: TCO information converts a multi-attribute decision into a single-attribute decision. Such information has the potential to reduce decision complexity, to correct biases in multi-attribute decisionmaking, and to make sure that the weight that each attribute receives in the overall decision is based on objective procedures. Not only in sourcing decisions, but also in settings of capital budgeting, or cost-benefit analysis for public policy, much supporting information consists of qualitative information and quantitative, non-monetary information, making it difficult to decide which alternative is the best one overall. Different attributes are non-comparable, because their measurement units are not commensurable. The translation of qualitative and non-monetary information into monetary units of measure facilitates cross-functional comparisons of alternatives.

However, not all attributes can be translated to their financial impact. Something gets lost in the translation to a common financial dimension, and some information is not translated at all (Galbraith 1973; Chapman 1997; Lillis 2002). Yet the benefits of quantitative financial summary 
data - they draw attention, are persuasive, suggest accuracy and objectivity, are easy to communicate, reduce the amount and diversity of information, make tradeoffs easy—could lead to loosing sight of nuances, paying less attention to subtle elements that are not included in the financial calculation, or making the non-financial information less credible. This could be a drawback of providing financial summary information. In other words: there could be unintended or even dysfunctional effects of providing better—but not perfect—costing information.

In this study, we will investigate what happens when some attribute information is included in the overall cost number, while other attribute information is not included. What is the effect on decision weights of these excluded attributes? We are particularly interested in the question whether information that is not compounded into aggregate financial information receives more or less weight as a result of providing such information. Decision makers can follow different strategies, which are likely to affect decision weights. They may focus on the overall TCO number, rather than on the individual attributes that comprise that number, and tradeoff the TCO number against the attributes that are not part of it. This categorization reduces the weight of the included attributes and increases the relative weight of the excluded attributes (Lipe and Salterio 2002). However, when the decision task becomes more demanding, applying this compensatory heuristic may be too difficult. Rather, decision makers may focus primarily on the TCO number and avoid making the difficult tradeoff with the non-financial attributes that are not compounded into the TCO number. This would reduce the weight of these excluded attributes. Such a reduction or increase of the weigh of these excluded attributes would be an unintended, and probably harmful, effect of providing the decision maker with TCO information. We will investigate complexity and experience as moderating variables. Despite the widespread attention for costing systems that include costs beyond direct costs, such as activity-based costing, customer profitability analysis, or TCO, the interaction of such information and 
managers' cognition has received little consideration (Lipe and Salterio 2000). ${ }^{1}$

Experiments were conducted with students and managers, 817 participants in total. The decision involved making a choice between two brands for a similar product. We found moderate support for our hypothesis H1: when complexity was low, providing decision makers with TCO information increased the decision weight of the excluded attribute. Looking at different levels of experience showed that this was only supported for participants with no business experience (undergraduate students), but not for participants with general business experience. We also found support for hypothesis H2: when complexity was high, the weight of the excluded attributes decreased as a result of providing TCO information, but only for the most experienced participants in the experiment.

The differences between students and practitioners suggest that experience may sometimes be a disadvantage. While experience could have enabled decision-makers to follow a more demanding, compensatory evaluation process at higher levels of complexity, the results suggest that, in contrast, experience could have been a disadvantage. Experience does not only imply expertise but also more familiarity with the task, which could have led more experienced decision makers to adopt a more straightforward evaluation process that was non-compensatory and that excessively relied on incomplete TCO information. As such, the results provided support for $\mathrm{H} 3 \mathrm{~b}$. In sum, these results suggest that providing incomplete TCO information has a significant impact on decision weights, which this differs for the complexity of the decision task and for the level of business experience of the decision maker.

The remainder of this paper is structured as follows. In the next section, the background of this paper is introduced in more detail and our hypotheses are developed. Subsequently, the research method is described, and results are presented. Discussion and conclusions are in the final section. 


\section{HYPOTHESES DEVELOPMENT}

Total cost of ownership aims to provide information that includes but goes beyond the mere purchase price and quantifies all costs involved in acquiring and using alternative purchase offerings. These costs may include transaction costs related to purchasing activities (e.g., ordering, freight, quality control), inventory-holding costs (e.g., capital, storage, handling, insurance, obsolescence), costs related to poor quality (e.g., rejection, rework, downtime, and warranties), or costs related to delivery failure to customers (Carr and Ittner 1992; Ellram 1995). Activities that are part of the scope of TCO should involve not only routine activities of the purchasing department (such as ordering items and making payments) but extend to more strategic activities of purchasing (such as supplier selection, developing relationships with important suppliers, participating in new product development). Furthermore, TCO activities occur within the purchasing department as well as in other departments (Armstrong 2002). As in activity-based costing, cost drivers can be at various levels, such as unit level (e.g., purchase price, quality control cost when each item must be inspected), batch level (e.g., costs of creating a purchase order, inspecting an order received), supplier sustaining level (e.g., cost of identification and certification of a supplier), and product or part sustaining level (e.g., cost of maintaining technical information on purchased parts).

Like all costing information, TCO is almost always an imperfect representation of the underlying decision problem, since not all aspects involved can be quantified perfectly in formalized, financial numbers (Galbraith 1973). Accounting information is an abstract and incomplete translation of real life processes and decision problems into numerical form (Chapman 1997). Some of the attributes of alternative offerings are not included in TCO systems, or are inaccurately included. For example, it may be that choosing a better quality supplier leads 
to lower costs for scrap, labor, inspection, and warranty, but that the cost accounting system is not able to accurately trace all these cost savings to that particular offering. It could be that, for example, only material, scrap, and labor costs savings are traced to products, while lower costs for inspection and warranty are shown at a higher level, such as for the total plant.

This paper investigates the effect of providing TCO information on decision weights in a multi-attribute sourcing decision when some attribute information is compounded (versus not compounded) into the TCO number. Consider the example in figures $1 \mathrm{~A}$ and $1 \mathrm{~B}$, which will also be used in the experiments. A sourcing decision requires choosing between two alternative machines. For each, information on four attributes is provided: lifetime, uptime, purchase price, and energy consumption. The total cost of ownership calculation (in terms of total cost per hour) is straightforward for purchase price and energy consumption, but the cost implications of downtime are typically much harder to determine and may very well be left out of the TCO calculation, as shown in figure 1 . Will the attribute that is not included in the TCO calculationuptime in this example-receive more, equal, or less weight when the TCO calculation is provided, compared to when no such information is provided?

[Insert figure 1 about here.]

The effect of TCO information on decision weights may depend on the decision strategy that decision-makers follow. We will discuss two different strategies: one implicating that decision weights of the excluded attributes will increase as a result of providing TCO information, and the other implying that the weights will be reduced. We will then discuss complexity and experience as moderating variables.

A first possible decision strategy could be to consider the attributes that are compounded in the TCO number as one category and to make a tradeoff with the excluded attributes. Categorizing information reduces information load and information diversity by combining 
information in categories that are meaningful to the decision maker. This allows decision makers focus on the category as a whole, rather than on the individual items within the group (Lipe and Salterio 2002). Accounting numbers, such as TCO, are often a meaningful basis for categorization. Within the category of attributes that are included in the TCO calculation, the provision of TCO information closely simulates a compensatory evaluation process. The individual part information tends to blend in the whole, stimulating the decision maker to focus on the category. Compared to the non-TCO situation, the few attributes that are not included will stand out and be more salient. In addition, the decision maker may assume that the attribute is left out for a reason, namely that it would be too important to be blend with others. At the extreme of such an evaluation process, the TCO number could be given about the same weight as each attribute that is not included, consistent with an equal weight heuristic (Dawes 1979; Einhorn and Hogarth 1975). The implication is that the relative weight of the attributes that are not included in the TCO number increases, compared to a situation of not providing the TCO information. Basically: in the example, uptime was one of three attributes in the non-TCO condition, and becomes one of two "attributes" or categories in the TCO condition.

A second, alternative evaluation process would be if decision-makers evaluate the options mainly based on a summary measure: the "bottom-line" TCO number. This decision strategy makes comparison and choice very easy, because it avoids making a tradeoff between attributes on different dimensions. There is only a tradeoff between attributes that are on the same financial dimension, and this tradeoff is captured in the TCO information and readily provided to the decision-maker. This is a "tempting" heuristic, because it is easy and because it is based on financial quantification, which carries much weight in decisions (Schiff and Hoffman 1996; Schiff and Bento 2000; Reck 2001; Ittner et al. 2003). This is particularly persuasive if the information is based on objective data (Kadous et al. 2004), such as in the case of TCO. If 
decision makers focus on the overall TCO number per alternative and more or less ignore attribute information that is not included in the "bottom-line" TCO number, then a lower weight for the non-included attribute would result. This would be an unintended, and probably harmful, effect of providing the decision maker with TCO information.

Decision makers tend to adjust their strategies to the requirements of the decision task, and when the task becomes more demanding, they need heuristics that simplify the information processing to a manageable level, while accepting that the decision may be further away from some optimal outcome (Bettman et al. 1998; Payne et al. 1993). Multi-attribute decisions are more demanding for human decision makers as the amount of information increases, as attributes are measured on a greater number of dissimilar dimensions, as the degree of conflict among attributes increases (the degree to which differing attributes indicate that different alternatives are the most desirable), as the number of shared attributes describing the options is smaller, as the amount of missing information increases, as the time available for processing the information decreases, and as the information display format becomes more complex (Bettman et al. 1998; Bonner 1994).

The first decision strategy considers more of the available information and is more difficult compared to the second, because it is compensatory and requires a difficult tradeoff between TCO and other attributes. The second decision strategy is a mix of compensatory and non-compensatory elements. However, the compensatory element is in the TCO number and it requires no effort on the part of the decision maker. In terms of a decision maker who adjusts the heuristic to the decision task, this second heuristic is essentially non-compensatory. In the TCO setting discussed here, we suggest that adaptive decision makers will try to use a compensatory, more comprehensive heuristic (the first), unless the task becomes too demanding and they must switch to the simpler, non-compensatory heuristic (the second). This is consistent with Shields 
(1980) who investigated the effect of decision complexity on decision strategy and found that managers were more likely to use non-compensatory decision-making strategies as decision complexity increased. So in other words: if decision makers realize that the TCO number is incomplete, they will be hesitant to base their decision only on that piece of information, unless the decision task is so demanding that they need to rely on such a strategy.

Complexity of the information provided is included as a moderating variable, because this affects how demanding the decision task is. If the level of complexity increases, decision makers might focus primarily on the TCO number, knowing that it is incomplete, but they may need such a "crude" decision strategy to make any decision at all.

The arguments presented above can be summarized in the following hypotheses:

H1: Providing the decision maker with TCO information of alternatives, increases the weight of an attribute that is not included in the TCO calculation, for low decision complexity.

H2: For high decision complexity, providing the decision maker with TCO information of alternatives reduces the weight of an attribute that is not included in the TCO calculation.

Experience is also a factor we expect to influence the results. For multi-attribute sourcing decisions in a business setting, decision makers with less business experience may respond differently compared to decision makers with more experience. It is, however, difficult to formulate a directional prediction, as will be discussed below. Experience implies not only expertise for executing a particular task, but also mere familiarity with the task (Alba and 
Hutchinson 1987). While more expertise may enable a decision maker to use a more difficult decision strategy (compared to a decision maker with less experience), more familiarity may at the same time lead decision makers to routinely apply a decision strategy that they are used to and to be less mindful about whether a particular decision strategy is appropriate for the specific task (Cohen et al. 1972). We will elaborate on these opposing predictions in the next paragraphs.

On the one hand, previous research in management accounting, auditing and consumer research has found benefits of experience in judgment and decision-making tasks (Dearman and Shields 2001). More experienced decision makers are better able to use complex information (large amounts, diverse attributes, incomplete, etc.) under difficult circumstances (time pressure, accountability, etc.) compared to less experienced decision makers (Bei and Widdows 1999; Bonner and Lewis 1990; Brucks 1985; Frederick 1991; Dorsey et al. 1999; Herz and Schultz 1999; Libby 1995; Spilker 1995; Shelton 1999; Vera-Muñoz, Kinney et al. 2001). Therefore, they need to take refuge to less "crude", approximate, or simplifying heuristics when confronted with the same information or under similar conditions as less experienced decision makers, and hence, they can make better decisions. When making a sourcing decision, experienced decisions makers may be better able to make the complex tradeoff between TCO and the excluded attributes. In other words: there is less of a need to switch to the non-compensatory strategy with lower decision weights for the excluded attributes. Results would support H1 more and H2 less for experienced compared to inexperienced decision makers.

On the other hand, experience can also be a drawback, because it may lead people to make decisions "as they always do" without considering sufficiently whether that is appropriate under the particular conditions. There is empirical evidence for detrimental effects of experience, resulting from a lack of fit between the knowledge structures recalled from memory and the given problem situation (Bédard and Chi 1992; Nelson et al. 1995). In the context of resource allocation 
decisions, Vera-Muñoz (1998) found that decision makers with high accounting knowledge are more likely to ignore opportunity costs than for decision makers with low accounting knowledge, because such knowledge may lead people to construct a problem representation based on their knowledge of GAAP-based rules that do not generally incorporate opportunity costs. In a similar way, general business experience may focus people's attention on costs as a dominant decision criterion that incorporates all relevant financial effects. More business experience could lead people to simply focus on lowest cost when comparing sourcing alternatives, especially when such information is readily available. More experienced decision makers would then more often follow a decision strategy primarily based on the overall TCO number, reducing the decision weight of the excluded attributes. If this inclination would be present, results would support H1 less and $\mathrm{H} 2$ more for experienced participants.

It is difficult to formulate a directional hypothesis for the effect of experience. While experience in the aforementioned studies typically pertains to knowledge about a specific task and its frequent execution (such as auditing and accounting tasks), experience in this study pertains to "general business experience". Little is know about the effects of more general experience on performance. Bonner and Lewis (1990) distinguish between world knowledge, general-domain knowledge, and subspecialty knowledge. We expect that general business experience is associated with world knowledge (which is gained through individual life experiences and education in general) and we expect this to affect how participants use accounting information, but we do not predict in which way. Therefore, two opposing hypotheses summarize the discussion:

H3a: Experienced decision makers are better able to tradeoff TCO information against attribute information that is not included in the TCO calculation (also at 
higher levels of complexity); hence for more experienced participants we expect stronger support for $\mathrm{H} 1$ and weaker support for $\mathrm{H} 2$ (compared to less experienced participants).

H3b: Experienced decision makers are more likely to focus on the TCO outcome and pay less attention to a tradeoff with attribute information that is not included in the TCO calculation; hence for experienced participants (compared to inexperienced participants) we expect weaker support for HI and stronger support for $\mathrm{H} 2$.

\section{RESEARCH METHOD}

In the experiments, participants were asked to make a purchasing decision. Participants received information about two brands of a machine. They were asked to compare both brands and to decide which brand they would purchase. For both brands, they received information on lifetime, uptime, purchase price, and electricity usage. The dependent variable is the choice for Brand $\mathrm{B}$, a dichotomous variable (Choice $B$ ).

The experiment used a $2 \times 2 \times 2$ between-participants design plus experience as a measured variable. The first factor that was manipulated was the availability of total cost information (TCO info), which is a dummy variable: See figure 1A for the information provided without total cost data; figure 1B shows the information including total cost data, which centers on the total cost per hour of each option, based on the purchase price and energy consumption. The total cost number did not include costs associated with the expected uptime of each brand, so "uptime" is the attribute that is not included in the costing system. ${ }^{2}$ 
The second factor was the uptime percentage of Brand B (Uptime B). For half of the participants in each experiment the uptime percentage of option B was set at $99.5 \%$. For the other half, this was set at $96.0 \%$. The interaction of the two independent variables TCO info and Uptime $B$ allows testing the hypotheses. Note that the preference for Brand B is expected to decrease as the uptime of Brand B decreases. If the preference for Brand B decreases more strongly in the TCO condition compared to the condition without TCO, then uptime (the attribute not included in the costing system) has a higher weight in the TCO condition compared to the non-TCO condition. Logistic regressions will be used with the basic following specification:

$$
\text { Choice } B=\beta_{0}+\beta_{1} \text { TCO info }+\beta_{2} \text { Uptime } B+\beta_{3}(\text { TCO info } \times \text { Uptime } B) \text {. }
$$

If the coefficient for the interaction of TCO info and Uptime B is significant and positive, then the effect of Uptime $B$ on the dependent variable Choice $B$ will be stronger if TCO info is available compared to when TCO info is not available. A negative coefficient indicates a lower weight.

The third factor was the level of complexity of the information provided (Complexity). The low-complexity condition was as described above, while in the high-complexity condition the number of attributes per option was increased by splitting the purchase price into four components. Instead of providing one purchase price of $€ 1,280$ for brand $A$, the prices of four separate components were given ( $€ 760, € 170, € 250, € 100)$ without giving the total purchase price, and this translated into four numbers in the TCO condition. The purchase price for brand B was separated in a similar way. See figures 1c and 1d for the information provided in conditions of high complexity, without and with TCO info.

Participants were either students or practitioners, and this difference will be used as a measured independent variable (Experience). Undergraduate students participated in this experiment, who were familiar with basic concepts of cost accounting. The information was 
provided on paper. Each participant made only one decision. The experiment was also conducted during two international trade fairs of technical and agricultural equipment and during a meeting of production and maintenance engineers. This allowed us to include participants who are users of cost accounting information, who had working experience, and who had an interest in technology and engineering. These participants are called "practitioners" in this paper. ${ }^{3}$ The total number of participants was 444 students and 373 practitioners, so 817 in total. In table 1 the number of participants in each condition is specified. ${ }^{4}$ In some of the analyses, Complexity and Experience are also included as main effects and interaction effects in the logistic regression.

[Insert table 1 about here.]

Participants received an introduction (which was identical in all conditions, see figure 2) and the information specific to their experimental condition. The introduction and the task were tested first in a pilot with 21 students for qualitative feedback on the task, and then in an experiment with 321 students to test different levels of uptime in the experimental task (99.5, $99.0,98.0$, and $96.0 \%)^{5}$

[Insert figure 2 about here.]

\section{RESULTS}

To investigate H1, we analyze the results for the low-complexity condition with all participants. We expect that the impact of uptime on the preference for brand B is stronger with TCO info compared to without TCO info. This effect is statistically tested using logistic regression. Results are in table 2, column 1 . The coefficient for the interaction of Uptime and TCO info was positive and statistically marginally significant $(\mathrm{p}=.096)$ providing moderate support for $\mathrm{H} 1$. The coefficient $\beta_{7}$ for the three-way interaction term was not significant. 
However, if we analyze the results for students and practitioners separately, we find differences between the two groups. Figure 3a suggests that for practitioners the weight is the same with or without TCO, while for students the weight increases as a result of providing TCO info. Indeed, the coefficient for the interaction of Uptime and TCO info for students was positive and marginally significant $(\mathrm{p}=.096)$ and not significant for practitioners (see column $1 \mathrm{a}$ and $1 \mathrm{~b}$ in table 2). In all, these results show moderate support for H1, overall and specifically for students, but no support for practitioners. ${ }^{6}$ Finding stronger support for H1 student participants than for practitioner participants is consistent with $\mathrm{H} 3 \mathrm{~b}$.

[Insert table 2 and figure 3 about here.]

To investigate $\mathrm{H} 2$, the results for high complexity are analyzed. Regression results in table 2, column 2 (same specification as above) show a highly significant coefficient for the three-way interaction term. Hence, we analyzed the results for the students and practitioners separately. The results in figure $3 b$ and the signs of the coefficients for the two-way interaction terms of Uptime and TCO info in columns $2 \mathrm{a}$ and $2 \mathrm{~b}$ of table 2 show that, for students providing TCO info increases the weight of uptime (contrary to H2), while for practitioners providing TCO info reduces the weight of TCO info (consistent with $\mathrm{H} 2$ ); and both effects are statistically significant. The fact that for $\mathrm{H} 2$, we find stronger support for practitioners than for students is also consistent with $\mathrm{H} 3 \mathrm{~b}$.

To summarize the results: $\mathrm{H} 1$ was moderately supported, but only for student-participants and not for practitioner-participants. $\mathrm{H} 2$ was strongly supported for practitioners, but was rejected for students. Students always gave greater weight to uptime as a result of being provided with TCO info, which is what we expected for low complexity (H1), but not for high complexity (H2). The way in which these findings for $\mathrm{H} 1$ and $\mathrm{H} 2$ differed between students and practitioners, provided support for $\mathrm{H} 3 \mathrm{~b}$, and not for the opposing hypothesis $\mathrm{H} 3 \mathrm{a}$. 


\section{Further Analysis of Practitioner Results}

The differences between the results for students and practitioners in this experiment suggests that that experience may be an important factor in understanding how human decisionmakers take cost information into account when making a difficult multi-attribute decision. We analyzed results within the group of practitioners to explore whether different levels of experience among practitioners are associated with different weights of cost information in their decision-making. In other words, are practitioners with less experience more similar to students, and practitioners with more experience more different from students? For this analysis we used two demographic characteristics collected from the practitioners: year of birth $(Y o B)$ and budget responsibility (Budget), which was formulated as follows: "How large is the budget for which

you are responsible? (€)” For year of birth, 372 participants provided an answer (out of 373), and for budget responsibility 249 participants answered. The data were split in two groups at the median $(Y o B=1961$ and Budget $=€ 1,000,000$, respectively). Responses for YoB and Budget at the median were allocated such that the differences in the number of observations per subgroup were minimized. ${ }^{7}$ Furthermore, there was only one observation in the entire Budget range between $€ 500,000$ and $€ 1,000,000$ and observations from $€ 1,000,000$ onwards ware more continuous, which provided another reason to include the responses for $€ 1,000,000$ with the higher budgets.

Results for low complexity, using the $Y o f B$ variable, are in figure 4a, which suggests that providing TCO info increases weight for the less experienced but not for the more experienced participants. Table 3, column 1 , shows that the coefficient of the three-way interaction term (Uptime $B \times T C O$ info $\times Y o f B)$ is marginally significant $(\mathrm{p}=.079)$, and results for both groups separately are not significant (column 1a and 1b). Results using the Budget variable are 
comparable; see columns $1,1 \mathrm{a}$, and $1 \mathrm{~b}$ in table 4 . The coefficient of the three-way interaction term (Uptime $B \times T C O$ info $\times$ Budget) is not significant, and results for both groups separately are not significant. ${ }^{8}$

[Insert tables 3 and 4, and figure 4 around here.]

As formulated in $\mathrm{H} 2$, we expect that for high decision complexity, providing the decision maker with TCO information of alternatives reduces the weight of an attribute that is not included in the TCO calculation. Results for high complexity, first using the YofB variable, are in figure $4 \mathrm{~b}$ and table 3. For less experienced participants, there appears to be no effect of providing TCO info on the weight of uptime (parallel lines) (no support for $\mathrm{H} 2$ ), while for more experienced participants the weight of uptime decreases when TCO info is provided (support for $\mathrm{H} 2$ ). The coefficient of the three-way interaction term is highly significant (column 2, $p=.014$ ). Results for the two groups separately indeed show that the coefficient of the two-way interaction term (Uptime $B \times T C O$ info) is not significant for less experienced participants (column 2a), but it is highly significant for more experienced participants (column $2 \mathrm{~b}, p=.006){ }^{9}$

Results for the Budget variable are very similar, see table 4. The three-way interaction term is highly significant (column $2, p=.007$ ). Looking at the results for both subgroups separately (column $2 \mathrm{a}$ and $2 \mathrm{~b}$ ), we find no significant two-way interaction for the subgroup with the lower budget responsibility, and a highly significant result for the subgroup with the higher budget responsibility ( $p=.011$ ), such that providing TCO info reduces the weight of uptime, which provides support for $\mathrm{H} 2 .^{10}$

The results are summarized in table 5. The further analysis of results within the group of practitioners provided no additional insights for H1. There was no support for this hypothesis for any of the subgroups identified within the practitioners that participated. However, some very 
interesting findings related to $\mathrm{H} 2$ were revealed. Results for the more experienced practitioners provided strong support for $\mathrm{H} 2$ (as we found for practitioners overall), while results for less experienced practitioners were not statistically significant. This suggests that experience is a key factor in understanding the use of cost information in complex multi-attribute decisions: $\mathrm{H} 2$ was supported for the most experienced subgroup of practitioners, results were not significant for the less experienced practitioners, and $\mathrm{H} 2$ needed to be rejected for students. This pattern of stronger support for $\mathrm{H} 2$ and weaker support for $\mathrm{H} 1$ as participants are more experienced is consistent with $\mathrm{H} 3 \mathrm{~b}$, and not with the opposing hypothesis $\mathrm{H} 3 \mathrm{a}$.

[Insert table 5 around here.]

\section{Further Discussion of Practitioners versus Students Results}

So far, we discussed the interaction effects in the results, in relation to testing of the hypotheses. Further insights may be gained from comparing the results for both groups of participants. Looking at figures $3 \mathrm{a}$ and $3 \mathrm{~b}$, it seems that when no TCO information is provided, the behavior of both groups converged. In the presence of TCO, however, both groups behaved markedly different.

Points on the left-hand sides of figures $3 \mathrm{a}$ and $3 \mathrm{~b}$ (high uptimes high for both alternatives) show that when no TCO info was provided, both groups chose alternative A and B about fiftyfifty (Choice $B$ was 45\%, 47\%, 52\%, and 58\%). However, when TCO information was provided, students chose B almost exclusively (91\%, 96\%), while practitioners' preference for B was smaller $(70 \%, 64 \%)$. This is surprising, as the provision of TCO info explicates that alternative B dominates $\mathrm{A}$ in those conditions: uptime of B is better (99.5\% versus $99.0 \%)$ and total cost per hour is lower ( $€ 0.65$ versus $€ 0.70$ ). A possible explanation for this result is that the attribute of life time was considered differently by practitioners compared to students. Note that life time was accounted for in the calculation of the total cost per hour, and we found that participants 
understood this calculation correctly. ${ }^{11}$ However, it may be that practitioners still considered the difference in life time, not because they would not understand that it was compounded into the TCO number, but just because it was included in the TCO number. Providing TCO info to practitioners may have provided a signal to them suggesting that those information elements that are included in the TCO number are more important than information elements that are not included it the TCO number. Life time is part of the TCO number and may, because of that, still carry a weight in the practitioner's decision-making. Uptime is not included, and this might be taken as a signal that it is less important. If this has happened, alternative B did not dominate A, because it was better on two attributes (uptime and total cost per hour), but not on life time. This might explain why practitioners on the left-hand sides of figures $3 a$ and $3 b$ when presented with TCO info did not overwhelmingly chose B, as students did.

The results in figures $4 \mathrm{a}$ and $4 \mathrm{~b}$ are consistent: the less experienced practitioners chose $\mathrm{B}$ more often (more similar to students) than the more experienced practitioners when TCO info was provided and uptime was high for both alternatives (on the left-hand sides of figures $4 \mathrm{a}$ and $4 b)$.

Additional qualitative and tentative findings suggested that the provision of TCO info may focus practioners' attention on TCO and the attributes included in it. We presented the experimental task to a group of 18 practioners during a meeting of a professional association of engineers working in maintenance management. The participants completed the experimental task and afterwards the researchers asked them to reflect on the task and on comparable decisions in their own organizations. The ensuing discussion was recorded and later transcribed. The exploratory impression emerging from this discussion is that the availability of TCO info shifts attention from uptime to costs. When discussing the task without TCO information, participants commented predominantly on uptime as the dominant criterion. (One participant worked in an 
environment where energy costs were a main cost, so he gave special attention to electricity usage.) However, when discussing the task with the provision of TCO information, the participants articulated the overriding importance of costs and factors that could be translated into costs. They also described that other so-called "non-financial" considerations may be considered earlier, as constraints that impact which set of alternatives is subsequently compared in terms of costs.

Points on the right-hand side (Uptime B at 96\%) of figure $3 \mathrm{~b}$ show that it made little difference to students whether or not TCO info was provided (21\% compared to $28 \%$ ), while it made much different to practitioners (10\% versus 43\%). As discussed above, part of the explanation might be that the provision of TCO info may have given a signal to practitioners on the high importance of costs and low importance of uptime (because it is not included in TCO info). However, the effect of providing TCO information is much more comparable across practitioners and students on the right-hand side of figure $3 \mathrm{a}$, when complexity is low, so something else may have been going on as well when complexity was high.

During the experiments it was observed students more often made calculations on paper, compared to practitioners. Without a calculation, the condition of Complexity high, no TCO, and Uptime $B$ at $96 \%$ was particularly demanding. The difference in life time was small, the differences in the four components of the purchase price and in energy consumption were difficult to consider consistently without a calculation on paper, and so the large difference in uptime between A and B may have drawn most attention of the decision-maker, to the disadvantage of $\mathrm{B}$. We can understand that few practitioners chose $\mathrm{B}$. The provision of TCO explicated that alternative B was superior in terms of cost per hour, and we suggest that this has not been considered by many practitioners, because they did not make the calculation. Against the significant disadvantage of B in terms of uptime, it was now clear that costs were lower. This 
may explain why the provision of TCO info, in this condition, made a much greater difference for practitioners than for students. When Complexity was low, it may not have mattered much whether or not participants made a calculation on paper. (As discussed above, for high Complexity and high Uptime B, the values on all attributes of A and B were rather comparable, and we can understand that both practitioners and student participants chose A and B about equally; see the left-hand side of figure $3 b$.

The results in figure $4 \mathrm{~b}$ are consistent: on the right-hand side the effect of providing TCO info is greater for the most experienced participants and smaller for the less experienced practitioners (they are more similar to students).

\section{CONCLUSIONS}

Alternative purchasing options can be described by several attributes. Some are financial in nature, and other attributes describe quality or functionality. Deciding which option to choose involves multi-attribute decision-making, and this is cognitively challenging for human decisionmakers. They adjust their decision strategies to the complexity of the particular decision they have to make. More complex decisions require decision strategies that reduce the complexity to a level that human decision makers can handle. TCO information may be used for this purpose.

We looked at decisions where participants, in an experimental setting, had to choose between two alternative purchase options ("Brand A" or "Brand B") that were both characterized by four attributes. In one half of all conditions, TCO information showed the total cost per hour on basis of three of the four attributes. We investigated the weight of the attribute that was not included as a result of providing the decision makers with TCO information. When given TCO information, would participants primarily look at the TCO numbers and pay less attention to the 
not-included attribute ("ignore" strategy), or would they rather tradeoff the TCO information against the non-included attribute and, hence, give more weight to that attribute ("tradeoff" strategy)? The "tradeoff" Strategy is more difficult than the "ignore" strategy. Therefore when complexity is low we expected that the "tradeoff" strategy would be used and the weight of the not-included attribute would increase (H1). When complexity is high, however, the decision strategy needs to be adjusted and we expected participants to use the less complex "ignore" strategy, leading to a lower weight of the not-included attribute as a result of providing the decision maker with TCO information (H2).

For low complexity (H1), results supported the hypothesis for all participants, but when broken down results were marginally supported for students and not for practitioners (no significant results). Within in the group of practitioners, neither the results for the less experienced, nor for the more experienced subgroup were significant. For high complexity, results supported $\mathrm{H} 2$ for practitioners as one group, and more strongly for the most experienced subgroup of practitioners; results were not significant for the less experienced practitioners; and H2 was rejected for students. This appears to be a consistent pattern, and taken together, these results strongly suggest that experience is an important determinant of the use of TCO information in complex multi-attribute decisions. The results also suggest that experienced decision makers, when provided with TCO information, become more likely to give a lower weight to attributes that are not compounded in the TCO calculation. This suggests that, as summarized in $\mathrm{H} 3 \mathrm{~b}$, experience may lead decision makers to focus more on TCO as the overall decision criterion and to be less sensitive to the incompleteness of such information.

The results of this study may have managerial implications for the introduction and use of TCO information, and other costing information that better captures the indirect costs of cost objects, but at the same time leaves out some important characteristics of these objects. Improved 
costing information that captures financial impact and aggregates financially quantifiable attributes may be helpful for the decision maker, but care should be give to unintended affectsthat those elements that are not included in the new costing information get less attention as a result of providing the information. This suggests that when introducing such information, it is important that the limitations should be explained very clearly to managers. It is probably also important to give a prominent position in costing reports to the excluded attributes. It might also be helpful to organize discussions about the new tradeoffs that are involved and to hold managers accountable for addressing the tradeoffs between financial and non-financial considerations.

Several limitations of this study should be mentioned. Participants were only asked to choose between two brands, but it was not clear how much more they preferred one option to the other. Several choices were driven by practical considerations to increase the number of participants needed for the sixteen different experimental conditions. The task was given to participants on paper so it would be possible to ask experienced participants during trade fairs. The advantage is that a large number of experienced participants participated, but it was not possible to measure decision time and other dependent variables that would have required doing the experimental task on a computer. The task took only a couple of minutes, because only a choice was asked and no qualitative data on why or how much one option was preferred. Again, this allowed including a high number of participants. Qualitative data on the decision process, for example through thinking aloud, might have given more insights into the decision strategies that participants followed and might have helped to explain the non-significant results for practitioners when complexity is low. However, with such a more time-consuming design it would not have been possible to have the same high number of participants.

Future research could focus on getting a better understanding of why under low complexity the provision of TCO information did not affect the weight that practitioners gave to 
the not-included attribute. Furthermore, as the results indicated that complexity is such an important variable for the use of incomplete costing information when making choices, a relevant question is whether other ways in which decision may be more or less demanding, will influence the use of costing information similarly. For example, how do time pressure and mental load influence the use of TCO? This would require a research plan in which thought processes are either traced or manipulated, and choices are recorded for the same participants. Only such a design would allow investigating whether and how these thought processes mediate the relationships between the experimental conditions and the participants' choices. A direct examination of the decision making process would be very interesting, and would require a different and much longer experimental task and better control of random environmental noise, probably only obtainable in a lab study with students (or other non-expert) participants.

Additionally, other ways in which costing information is not "perfect" could be considered. Incompleteness in a TCO setting is central to this study, and imperfections in TCO systems could be modeled differently in future research. For example, certain attributes might be included in a TCO number, but inaccurately. Are results for inaccurate TCO information similar to incomplete TCO information, which was investigated here? And finally, while in this study individual decision-making has been investigated; future research could also investigate the use of costing information in relation to complexity for decisions that are taken in a social context. 


\section{REFERENCES}

Alba, J. W., and J. W. Hutchinson. 1987. Dimensions of consumer expertise. Journal of Consumer Research 13 (4): 411-454.

Armstrong, P. 2002. The costs of activity-based management. Accounting, Organizations and Society 27 (1/2): 99-120.

Bédard, J., and M. T. H. Chi. 1992. Expertise. Current Directions in Psychological Science 1 (4): 135139.

Bei, L. T., and R. Widdows. 1999. Product knowledge and product involvement as moderators of the effects of information on purchase decisions: a case study using the perfect information frontier approach. The Journal of Consumer Affairs 33 (1): 165-186.

Bettman, J. R., M. F. Luce, and J. W. Payne. 1998. Constructive consumer choice processes. Journal of Consumer Research 25 (3): 187-217.

Blocher, E., R. P. Moffie, and R. W. Zmud. 1986. Report format and task complexity: interaction in risk judgements. Accounting, Organizations and Society 11 (6): 457-470.

Bonner, S.E. 1994. A model of the effects of audit task complexity. Accounting, Organizations and Society 19 (3): 213-234.

Bonner, S. E., and B. L. Lewis. 1990. Determinants of auditor expertise. Journal of Accounting Research 28 (Supplement): 1-20.

Brucks, M. 1985. The effects of product class knowledge on information search behavior. The Journal of Consumer Research 12 (1): 1-16.

Carr, L. P., and C. D. Ittner. 1992. Measuring the cost of ownership. Journal of Cost Management 6 (3): $42-51$. 
Chapman, C.S. 1997. Reflections on a contingent view of accounting. Accounting, Organizations and Society 22 (2): 189-206.

Cohen, M. D., J. G. March, and J. P. Olsen. 1972. A garbage can model of organizational choice. Administrative Science Quarterly 17 (1): 1-25.

Dawes, R. M. 1979. The robust beauty of improper linear models in decision making. American Psychologist 34 (7): 571-583.

Dearman, D. T., and M. D. Shields. 2001. Cost knowledge and cost-based judgment performance. Journal of Management Accounting Research 13: 1-18.

Dorsey, D. W., G. E. Campbell, L. L. Foster, and D. E. Miles. 1999. Assessing knowledge structures: relations with experience and posttraining performance. Human Performance 12 (1): 31-57.

Einhorn, H. J., and R. M. Hogarth. 1975. Unit weighting schemes for decision making. Organizational Behavior and Human Performance 13 (2): 171-192.

Ellram, L. M. 1995. Activity-based costing and total cost of ownership: a critical linkage. Journal of Cost Management 8 (4): 22-30.

Frederick, D. M. 1991. Auditors' representation and retrieval of internal control knowledge. The Accounting Review 66 (2): 240-258.

Galbraith, J. 1973. Designing Complex Organizations. New York, NY: Addison-Wesley.

Herz, P. J., and J. J. Schultz, Jr. 1999. The role of procedural and declarative knowledge in performing accounting tasks. Behavioral Research in Accounting 11: 1-26.

Iselin, E. R. 1988. The effects of information load and information diversity on decision quality in a structured decision task. Accounting, Organizations and Society 13 (2): 147-164.

Ittner, C. D., D. F. Larcker, and M. W. Meyer. 2003. Subjectivity and the weighting of performance measures: evidence from balanced scorecard. The Accounting Review 78 (3): 725-758. 
Kadous, K., L. Koonce, and K. L. Towry. 2004. Quantification and persuasion in managerial judgment. Working paper, University of Texas.

Libby, R. 1995. The role of knowledge and memory in audit judgment. In Judgment and Decision-Making Research in Accounting and Auditing, edited by R. H. Ashton and A. H. Ashton, 176-206. New York, NY: Cambridge University Press.

Lillis, A. M. 2002. Managing multiple dimensions of manufacturing performance - an exploratory study. Accounting, Organizations and Society 27 (6): 497-529.

Lipe, M., and S. Salterio. 2000. The balanced scorecard: judgmental effects of common and unique performance measures. The Accounting Review 75 (3): 283-298.

Lipe, M., and S. Salterio. 2002. A note on the judgmental effects of the balanced scorecard's information organization. Accounting, Organizations and Society 27 (6): 531-540

Nelson, M. W., R. Libby, S. E. Bonner. 1995. Knowledge structure and the estimation of conditional probabilities in audit planning. The Accounting Review 70 (1): 27-47.

Payne, J. W., J. R. Bettman, and E. J. Johnson. 1993. The Adaptive Decision Maker. Cambridge, MA: Cambridge University Press.

Reck, J. L. 2001. The usefulness of financial and nonfinancial performance information in resource allocation decisions. Journal of Accounting and Public Policy 20 (1): 45-71.

Schiff, A. D., and R. F. Bento. 2000. The use of financial and nonfinacial information for evaluating performance: an attributional perspective. Journal of Applied Business Research 16 (4): 47-62.

Schiff, A. D., and L. R. Hoffman. 1996. An exploration of the use of financial and nonfinancial measures of performance by executives in a service organization. Behavioral Research in Accounting 8: 134153. 
Shelton, S. W. 1999. The effect of experience on the use of irrelevant evidence in auditor judgment. The Accounting Review 74 (2): 217-224.

Shields, M. D. 1980. Some effects of information load on search patterns used to analyze performance reports. Accounting, Organizations and Society 5 (4): 429-442.

Shields, M. D. 1983. Effects of information supply and demand on judgment accuracy: evidence from corporate managers. The Accounting Review 58 (2): 284-303.

Shields, M. D., J. G. Birnberg, and I. H. Frieze. 1981. Attributions, cognitive processes and control systems. Accounting, Organizations and Society 6 (1): 69-93.

Spilker, B. C. 1995. The effect of time pressure and knowledge on key word selection behavior in tax research. The Accounting Review 70 (1): 49-70.

Vera-Muñoz, S. C. 1998. The effects of accounting knowledge and context on the omission of opportunity costs in resource allocation decisions. The Accounting Review 73 (1): 47-72.

Vera-Muñoz, S. C., W. R. Kinney, Jr., and S. E. Bonner .2001. The effects of domain experience and task presentation format on accountants' information relevance assurance. The Accounting Review 76 (3): 405-429. 


\section{Table 1}

Total number of participants (and number of participants choosing brand B) per condition

\begin{tabular}{|c|c|c|c|c|c|c|c|c|c|}
\hline Complexity & & \multicolumn{4}{|c|}{ Low } & \multicolumn{4}{|c|}{ High } \\
\hline TCO info & & \multicolumn{2}{|c|}{ No TCO } & \multicolumn{2}{|c|}{$\mathrm{TCO}$} & \multicolumn{2}{|c|}{ No TCO } & \multicolumn{2}{|c|}{$\mathrm{TCO}$} \\
\hline Experience & & Students & Practitioners & Students & Practitioners & Students & Practitioners & Students & Practitioners \\
\hline \multirow[t]{3}{*}{ Uptime B } & $96.0 \%$ & 57 (6) & $41(6)$ & $55(15)$ & 48 (16) & $61(13)$ & $48(5)$ & $54(15)$ & $46(20)$ \\
\hline & $99.5 \%$ & $64(30)$ & $47(21)$ & $54(49)$ & $47(33)$ & $53(31)$ & $46(24)$ & $46(44)$ & $50(32)$ \\
\hline & Total & 121 & 88 & 109 & 95 & 114 & 94 & 100 & 96 \\
\hline
\end{tabular}


Table 2

Logistic regression results of experiments with students and practitioners

\begin{tabular}{|c|c|c|c|c|c|c|}
\hline & $\begin{array}{c}(1) \\
\text { Complexity } \\
\text { low, } \\
N=413\end{array}$ & $\begin{array}{c}(2) \\
\text { Complexity } \\
\text { high, } \\
N=404\end{array}$ & $\begin{array}{c}\text { (1a) } \\
\text { Complexity } \\
\text { low, } \\
\text { Students, } \\
N=230\end{array}$ & $\begin{array}{c}(1 \mathrm{~b}) \\
\text { Complexity } \\
\text { low, } \\
\text { Practitioners } \\
N=183\end{array}$ & $\begin{array}{c}(2 \mathrm{a}) \\
\text { Complexity } \\
\text { high, } \\
\text { Students, } \\
N=214\end{array}$ & $\begin{array}{c}\text { (2b) } \\
\text { Complexity } \\
\text { high, } \\
\text { Practitioners } \\
N=190\end{array}$ \\
\hline Constant & $\begin{array}{c}-57.406 \\
(.000)\end{array}$ & $\begin{array}{c}-46.541 \\
(.000)\end{array}$ & $\begin{array}{c}-57.406 \\
(.000)\end{array}$ & $\begin{array}{c}-44.278 \\
(.003)\end{array}$ & $\begin{array}{c}-46.541 \\
(.000)\end{array}$ & $\begin{array}{c}-63.558 \\
(.000)\end{array}$ \\
\hline Uptime B & $\begin{array}{l}57.569 \\
(.000)\end{array}$ & $\begin{array}{l}47.120 \\
(.000)\end{array}$ & $\begin{array}{l}57.569 \\
(.000)\end{array}$ & $\begin{array}{l}44.286 \\
(.003)\end{array}$ & $\begin{array}{l}47.120 \\
(.000)\end{array}$ & $\begin{array}{l}63.965 \\
(.000)\end{array}$ \\
\hline TCO info & $\begin{array}{l}-33.080 \\
(.114)\end{array}$ & $\begin{array}{l}-65.405 \\
(.008)\end{array}$ & $\begin{array}{c}-33.080 \\
(.114)\end{array}$ & $\begin{array}{l}1.054 \\
(.957)\end{array}$ & $\begin{array}{c}-65.405 \\
(.008)\end{array}$ & $\begin{array}{l}40.318 \\
(.039)\end{array}$ \\
\hline Experience & $\begin{array}{l}13.128 \\
(.522)\end{array}$ & $\begin{array}{c}-17.017 \\
(.385)\end{array}$ & & & & \\
\hline Uptime $B \times T C O$ info & $\begin{array}{l}35.666 \\
(.096)\end{array}$ & $\begin{array}{l}68.496 \\
(.007)\end{array}$ & $\begin{array}{l}35.666 \\
(.096)\end{array}$ & $\begin{array}{l}.017 \\
(.999)\end{array}$ & $\begin{array}{l}68.496 \\
(.007)\end{array}$ & $\begin{array}{c}-40.030 \\
(.044)\end{array}$ \\
\hline Uptime $B \times$ Experience & $\begin{array}{c}-13.283 \\
(.523)\end{array}$ & $\begin{array}{l}16.845 \\
(.398)\end{array}$ & & & & \\
\hline TCO info $\times$ Experience & $\begin{array}{l}34.135 \\
(.231)\end{array}$ & $\begin{array}{c}105.723 \\
(.001)\end{array}$ & & & & \\
\hline $\begin{array}{l}\text { Uptime } B \times \text { TCO info } \times \\
\text { Experience }\end{array}$ & $\begin{array}{c}-35.649 \\
(.221)\end{array}$ & $\begin{array}{c}-108.526 \\
(.001)\end{array}$ & & & & \\
\hline
\end{tabular}

Logistic regressions, values of coefficients (and $p$-values for two-tailed Wald test) 
Table 3

Further analyses of practitioners results, based on year of birth

\begin{tabular}{|c|c|c|c|c|c|c|}
\hline & $\begin{array}{c}(1) \\
\text { Complexity } \\
\text { low, } \\
N=183\end{array}$ & $\begin{array}{c}(2) \\
\text { Complexity } \\
\text { high, } \\
N=189\end{array}$ & $\begin{array}{c}\text { (1a) } \\
\text { Complexity } \\
\text { low, } \\
\text { Yof } B \geq 1961 \\
N=96\end{array}$ & $\begin{array}{c}\text { (1b) } \\
\text { Complexity } \\
\text { low, } \\
\text { YofB } \leq 1960 \\
N=87\end{array}$ & $\begin{array}{c}(2 \mathrm{a}) \\
\text { Complexity } \\
\text { high, } \\
\text { YofB } \geq 1961 \\
N=96\end{array}$ & $\begin{array}{c}(2 \mathrm{~b}) \\
\text { Complexity } \\
\text { high, } \\
\text { YofB } \leq 1960 \\
N=93\end{array}$ \\
\hline Constant & $\begin{array}{c}-38.097 \\
(.067)\end{array}$ & $\begin{array}{c}-51.078 \\
(.009)\end{array}$ & $\begin{array}{c}-38.097 \\
(.067)\end{array}$ & $\begin{array}{l}-49.199 \\
(.024)\end{array}$ & $\begin{array}{c}-51.078 \\
(.009)\end{array}$ & $\begin{array}{c}-86.551 \\
(.006)\end{array}$ \\
\hline Uptime B & $\begin{array}{l}38.080 \\
(.071)\end{array}$ & $\begin{array}{l}51.430 \\
(.010)\end{array}$ & $\begin{array}{l}38.080 \\
(.071)\end{array}$ & $\begin{array}{l}49.222 \\
(.027)\end{array}$ & $\begin{array}{l}51.430 \\
(.010)\end{array}$ & $\begin{array}{l}86.986 \\
(.006)\end{array}$ \\
\hline TCO info & $\begin{array}{l}-38.239 \\
(.193)\end{array}$ & $\begin{array}{c}-11.564 \\
(.671)\end{array}$ & $\begin{array}{c}-38.239 \\
(.193)\end{array}$ & $\begin{array}{l}32.578 \\
(.242)\end{array}$ & $\begin{array}{c}-11.564 \\
(.671)\end{array}$ & $\begin{array}{l}97.983 \\
(.005)\end{array}$ \\
\hline YofB & $\begin{array}{l}-11.102 \\
(.713)\end{array}$ & $\begin{array}{l}-35.474 \\
(.335)\end{array}$ & & & & \\
\hline Uptime $B \times T C O$ info & $\begin{array}{l}40.383 \\
(.179)\end{array}$ & $\begin{array}{l}12.677 \\
(.647)\end{array}$ & $\begin{array}{l}40.383 \\
(.179)\end{array}$ & $\begin{array}{l}-32.141 \\
(.257)\end{array}$ & $\begin{array}{l}12.677 \\
(.647)\end{array}$ & $\begin{array}{c}-98.571 \\
(.006)\end{array}$ \\
\hline Uptime $B \times Y o f B$ & $\begin{array}{l}11.142 \\
(.716)\end{array}$ & $\begin{array}{l}35.556 \\
(.340)\end{array}$ & & & & \\
\hline TCO info $\times$ YofB & $\begin{array}{l}70.817 \\
(.080)\end{array}$ & $\begin{array}{c}109.546 \\
(.014)\end{array}$ & & & & \\
\hline $\begin{array}{l}\text { Uptime } B \times \text { TCO info } \times \\
\text { YofB }\end{array}$ & $\begin{array}{l}-72.524 \\
(.079)\end{array}$ & $\begin{array}{c}-111.248 \\
(.014)\end{array}$ & & & & \\
\hline
\end{tabular}

Logistic regressions: values of coefficients and $p$-values (for two-tailed Wald test) are tabulated. The total number practitioners was 373, and 372 answered the question about their year of birth. The median response was 1960. 


\section{Table 4}

Further analysis of Practitioner results, based on budget responsibility

\begin{tabular}{|c|c|c|c|c|c|c|}
\hline & $\begin{array}{c}(1) \\
\text { Complexity } \\
\text { low, } \\
N=120\end{array}$ & $\begin{array}{c}(2) \\
\text { Complexity } \\
\text { high, } \\
N=129\end{array}$ & $\begin{array}{c}\text { (1a) } \\
\text { Complexity } \\
\text { low, } \\
\text { Budget } \leq \\
€ 800,000 \\
N=62\end{array}$ & $\begin{array}{c}(1 \mathrm{~b}) \\
\text { Complexity } \\
\text { low, } \\
\text { Budget } \geq \\
€ 1,000,000 \\
N=58\end{array}$ & $\begin{array}{c}(2 a) \\
\text { Complexity } \\
\text { high, } \\
\text { Budget } \leq \\
€ 800,000 \\
N=55\end{array}$ & $\begin{array}{c}(2 \mathrm{~b}) \\
\text { Complexity } \\
\text { high, } \\
\text { Budget } \geq \\
€ 1,000,000 \\
N=74\end{array}$ \\
\hline Constant & $\begin{array}{c}-65.459 \\
(.041)\end{array}$ & $\begin{array}{l}-27.569 \\
(.244)\end{array}$ & $\begin{array}{c}-65.459 \\
(.041)\end{array}$ & $\begin{array}{c}-58.213 \\
(.033)\end{array}$ & $\begin{array}{c}-27.569 \\
(.244)\end{array}$ & $\begin{array}{c}-64.502 \\
(.012)\end{array}$ \\
\hline Uptime B & $\begin{array}{l}65.788 \\
(.042)\end{array}$ & $\begin{array}{l}27.574 \\
(.253)\end{array}$ & $\begin{array}{l}65.788 \\
(.042)\end{array}$ & $\begin{array}{l}58.689 \\
(.034)\end{array}$ & $\begin{array}{l}27.574 \\
(.253)\end{array}$ & $\begin{array}{l}64.960 \\
(.012)\end{array}$ \\
\hline TCO info & $\begin{array}{l}23.565 \\
(.549)\end{array}$ & $\begin{array}{c}-48.500 \\
(.178)\end{array}$ & $\begin{array}{l}23.565 \\
(.549)\end{array}$ & $\begin{array}{l}-42.091 \\
(.216)\end{array}$ & $\begin{array}{c}-48.500 \\
(.178)\end{array}$ & $\begin{array}{l}82.334 \\
(.010)\end{array}$ \\
\hline Budget & $\begin{array}{l}7.246 \\
(.863)\end{array}$ & $\begin{array}{c}-36.932 \\
(.289)\end{array}$ & & & & \\
\hline Uptime $B \times T C O$ info & $\begin{array}{l}-22.499 \\
(.573)\end{array}$ & $\begin{array}{l}47.799 \\
(.174)\end{array}$ & $\begin{array}{c}-22.499 \\
(.573)\end{array}$ & $\begin{array}{l}41.895 \\
(.228)\end{array}$ & $\begin{array}{l}47.799 \\
(.174)\end{array}$ & $\begin{array}{c}-82.714 \\
(.011)\end{array}$ \\
\hline Uptime $B \times$ Budget & $\begin{array}{l}-7.099 \\
(.868)\end{array}$ & $\begin{array}{l}37.386 \\
(.292)\end{array}$ & & & & \\
\hline TCO info $\times$ Budget & $\begin{array}{l}18.526 \\
(.722)\end{array}$ & $\begin{array}{c}130.835 \\
(.006)\end{array}$ & & & & \\
\hline $\begin{array}{l}\text { Uptime } B \times \text { TCO info } \times \\
\text { Budget }\end{array}$ & $\begin{array}{c}-19.397 \\
(.714)\end{array}$ & $\begin{array}{c}-132.513 \\
(.007)\end{array}$ & & & & \\
\hline
\end{tabular}

Logistic regressions: values of coefficients and $p$-values (for two-tailed Wald test) are tabulated. The total number of practitioners was 373, of which 249 answered the question about their budget responsibility. The median response was $€ 1,000,000$, and there were no responses for Budget between $€ 800,000$ and $€ 1,000,000$. 
Table 5

\section{Summary of findings}

\begin{tabular}{|c|c|c|c|c|c|c|c|}
\hline & \multirow{5}{*}{$\begin{array}{c}\text { All } \\
\text { participants }\end{array}$} & \multirow[b]{5}{*}{ Students } & \multirow[b]{5}{*}{ Practitioners } & \multirow{5}{*}{$\begin{array}{c}\text { Less } \\
\text { experienced } \\
\text { practitioners } \\
\text { YofB } \geq 1961\end{array}$} & \multirow{5}{*}{$\begin{array}{c}\text { More } \\
\text { experienced } \\
\text { practitioners } \\
\text { YofB } \leq 1960\end{array}$} & \multirow{3}{*}{$\begin{array}{c}\text { Less } \\
\text { experienced } \\
\text { practitioners }\end{array}$} & \multirow{3}{*}{$\begin{array}{c}\text { More } \\
\text { experienced } \\
\text { practitioners }\end{array}$} \\
\hline & & & & & & & \\
\hline & & & & & & & \\
\hline & & & & & & Budget $\leq$ & Budget $\geq$ \\
\hline & & & & & & $€ 800,000$ & $€ 1,000,000$ \\
\hline $\mathrm{H} 1$ & $\begin{array}{l}\text { Moderate } \\
\text { support }\end{array}$ & $\begin{array}{l}\text { Moderate } \\
\text { support }\end{array}$ & No support & No support & No support & No support & No support \\
\hline $\mathrm{H} 2$ & No support & Rejected & $\begin{array}{l}\text { Strong } \\
\text { support }\end{array}$ & No support & $\begin{array}{l}\text { Strong } \\
\text { support }\end{array}$ & No support & $\begin{array}{l}\text { Strong } \\
\text { support }\end{array}$ \\
\hline
\end{tabular}

$\mathrm{H} 3$

This pattern of weaker support for $\mathrm{H} 1$ and stronger support for $\mathrm{H} 2$ as participants are more experienced is consistent with $\mathrm{H} 3 \mathrm{~b}$, and not with the opposing hypothesis H3a. 


\section{Figure 1}

\section{Information provided for multi-attribute decision-making in experimental task}

Figure 1a: no TCO info provided, complexity low

\begin{tabular}{lrr} 
& Brand A & Brand B \\
\hline Life time (hours) & 2,900 & 2,800 \\
Uptime (\%) & $99.0 \%$ & $96.0 \%$ \\
Purchasing price $(€)$ & $€ 1,280$ & $€ 1,020$ \\
Energy per hour (Kwh) & 2.0 & 2.2
\end{tabular}

Figure 1b: TCO info provided, complexity low

Energy cost (Kwh) $\quad € 0.13$

\begin{tabular}{lrr|rr} 
& Brand A & Cost per hour & Brand B & Cost per hour \\
\hline Life time (hours) & 2,900 & & 2,800 & \\
Uptime (\%) & $99.0 \%$ & & $96.0 \%$ & \\
Purchasing price ( $€$ ) & $€ 1,280$ & $€ 0.44$ & $€ 1,020$ & $€ 0.36$ \\
Energy per hour (Kwh) & 2.0 & $€ 0.26$ & 2.2 & $€ 0.29$ \\
Total cost per hour & & $€ 0.70$ & & $€ 0.65$ \\
\end{tabular}

Figure 1c: no TCO info provided, complexity high

\begin{tabular}{lrrr} 
& & Brand A & Brand B \\
\hline Life time (hours) & & 2,900 & 2,800 \\
Uptime (\%) & $99.0 \%$ & $96.0 \%$ \\
Purchasing price $(€)$ & Component A & $€ 760$ & $€ 560$ \\
& Component B & $€ 170$ & $€ 190$ \\
& Component C & $€ 250$ & $€ 160$ \\
& Component D & $€ 100$ & $€ 110$ \\
Energy per hour (Kwh) & 2.0 & 2.2
\end{tabular}

Figure 1d: TCO info provided, complexity high

Energy cost (Kwh)

$€ 0.13$

\begin{tabular}{|c|c|c|c|}
\hline Brand A & Cost per hour & Brand B & Cost per hour \\
\hline 2,900 & & 2,800 & \\
\hline $99.0 \%$ & & $96.0 \%$ & \\
\hline$€ 760$ & $€ 0.26$ & $€ 560$ & $€ 0.20$ \\
\hline$€ 170$ & $€ 0.06$ & $€ 190$ & $€ 0.07$ \\
\hline$€ 250$ & $€ 0.09$ & $€ 160$ & $€ 0.06$ \\
\hline$€ 100$ & $€ 0.03$ & $€ 110$ & $€ 0.04$ \\
\hline 2.0 & $€ 0.26$ & 2.2 & $€ 0.29$ \\
\hline & $€ 0.70$ & & $€ 0.65$ \\
\hline
\end{tabular}




\section{Figure 2}

Text introducing the experimental task

"You are the manager of a production department. One machine has to be renewed. You can choose between two brands, both meet all specifications.

In the table below information is provided about: the purchasing price of a new machine, the lifetime of a new machine, energy consumption per hour, and the uptime percentage of the machine. The 'uptime (\%)' is the percentage of the time the machine is available for production. $100 \%$ - 'uptime $(\%)$ ' = 'downtime (\%)'. Downtime is caused by machine failure, maintenance, etc. that cause rescheduling of production, not meeting delivery times, etc.

Indicate which brand you will buy: 


\section{Figure 3}

Students versus practitioners

Figure 3a: Complexity low

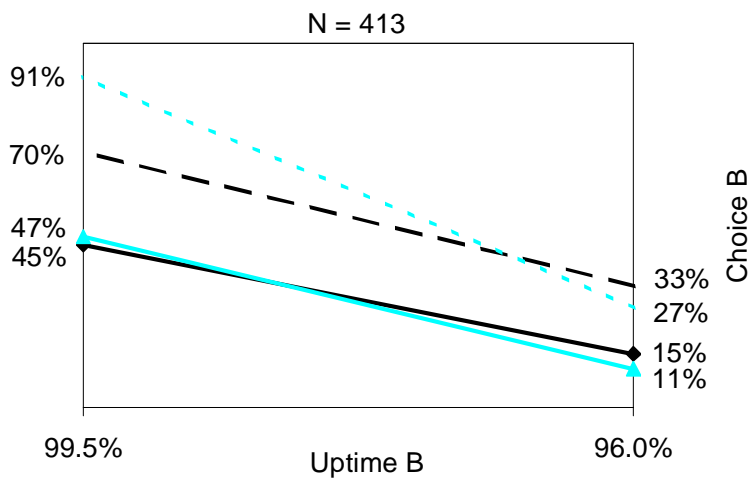

$\rightarrow$ Practitioners No TCO - - Practitioners TCO

$\rightarrow$ Students No TCO $\quad$ - - - Students TCO
Figure 3b: Complexity high

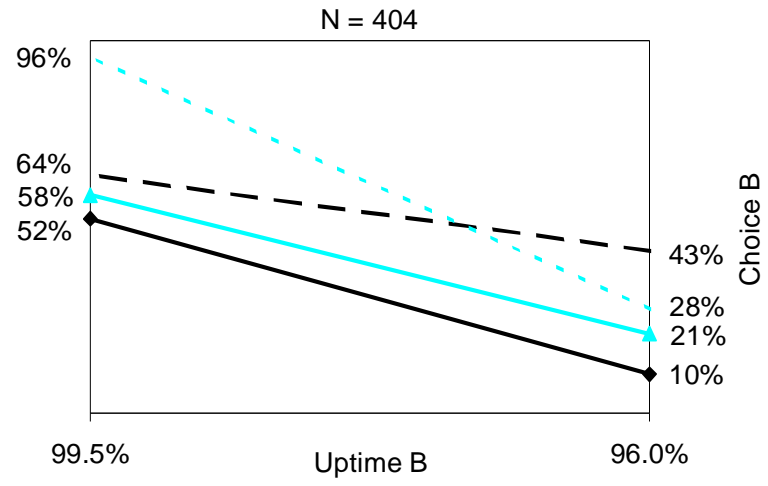

$\rightarrow$ Practitioners No TCO - -Practitioners TCO $\rightarrow$ Students No TCO - - Students TCO 


\title{
Figure 4
}

Less experienced practitioners versus more experienced practitioners,

\author{
based on year-of-birth
}

Figure 4a: Complexity low

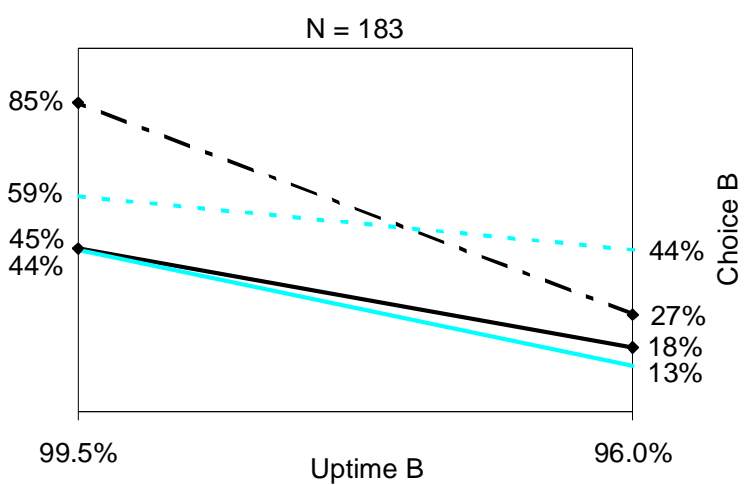

$\rightarrow$ No TCO $($ YofB $\geq 1961) \longrightarrow-$ TCO $($ YofB $\geq 1961)$

- No TCO $($ YofB $\leq 1960)=-$ TCO $($ YofB $\leq 1960)$
Figure 4b: Complexity high

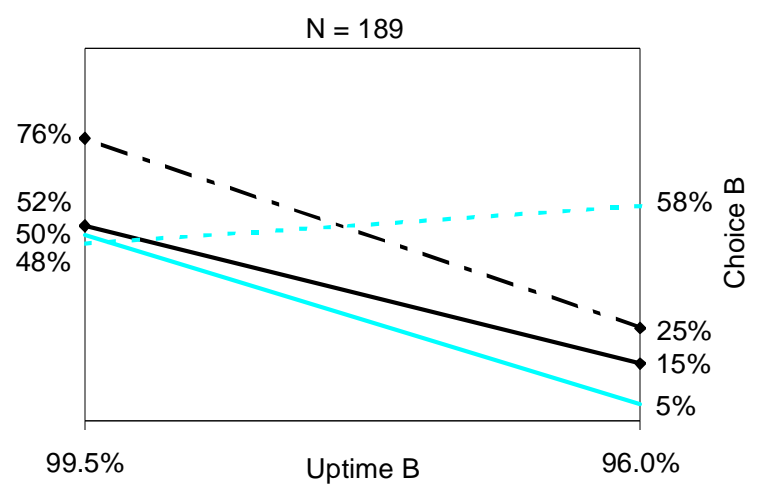

$\rightarrow$ No TCO $($ YofB $\geq 1961) \rightarrow-$ TCO $($ YofB $\geq 1961)$

- No TCO $($ YofB $\leq 1960)=-$ TCO $($ YofB $\leq 1960)$ 
${ }^{1}$ Some early studies on how decision makers use financial and non-financial information include Blocher et al. (1986), Iselin (1988), Shields (1983), Shields et al. (1981).

${ }^{2}$ We tested whether participants correctly understood this information, in particular that no cost consequences of downtime were included in the TCO number. A sample of practitioners and students was asked, after completing the task, to provide a short written explanation of how two components of the TCO number were calculated; $86 \%$ of the answers treated uptime correctly in the calculation. An additional $4 \%$ of the calculations was not correct but it but still demonstrated that the participant understood that uptime is not fully considered in the provided TCO information.

${ }^{3}$ Visitors of these trade fairs were asked if they were willing to answer a short question for a research project, which would only take a few minutes. A participant received one sheet of paper with the experimental task on one side, and background questions about the participant on the other side. The participant completed the task with the researcher present and filled out the background questions. If requested, the researcher explained the research project after completing the task. Each person participated only once and was randomly assigned to an experimental condition. From our observations, we have the distinct impression that participants attended seriously to the task.

${ }^{4}$ With some international participants we used an English version of the experimental task. To check the translation, the task was translated from Dutch to English and then translated back to Dutch independently by two people who had not been involved in the first translation. The translation was similar to the original formulation.

${ }^{5}$ During the main experiment it was also tested whether another ordering of attributes, with uptime as the last attribute, influenced the outcomes. We included a condition with this alternative ordering (with students, low complexity, 119 participants). Results (not tabulated) showed that none of the interaction terms that included "order" had significant coefficients.

${ }^{6}$ The pilot experiment gave similar results. This involved only students and low complexity. The coefficient of the interaction term TCO info $\times$ Uptime $B$ was statistically significant at $p=.056$, providing moderate support for $\mathrm{H} 1$. ${ }^{7}$ Including observations for $Y o B=1961$ in columns $1 \mathrm{~b}$ and $2 \mathrm{~b}$ of table 3, would make the observations more uneven: 86 and 97 for columns 1a and $1 \mathrm{~b}$ (difference of 11) and 87 and 102 for columns 2a and 2b (difference of 15), giving a total difference of 26 compared to $9+3=12$ in the current table. Including observations for Budget $=€ 1,000,000$ in columns 1a and 2a of table 4, would also make the observations more uneven: 72 and 48 for columns 1a and $1 \mathrm{~b}$ 
(difference of 24) and 68 and 61 for columns $2 \mathrm{a}$ and $2 \mathrm{~b}$ (difference of 7), giving a total difference of 31 compared to $4+19=23$ in the current table.

${ }^{8}$ These conclusions remain unchanged when the allocation of observations at the median is changed.

${ }^{9}$ These conclusions remain unchanged when the allocation of observations at the median is changed.

${ }^{10}$ These conclusions are not significant when the allocation of observations at the median is changed.

${ }^{11}$ We tested whether participants understood correctly that the TCO calculation had taken care of the difference in life time. Students $(n=43)$ and practitioners $(n=24)$ were asked to explain the calculation of the purchase price per hour, as provided in the experimental task. Results indicated that $94 \%$ of the participants showed they correctly understood that life time was in the denominator of the calculation of the purchase price per hour. 